\title{
Editorial 25/1: 25 years of electronic markets
}

\author{
Rainer Alt • Carsta Militzer-Horstmann • \\ Hans-Dieter Zimmermann
}

Published online: 3 March 2015

(C) Institute of Information Management, University of St. Gallen 2015

Dear readers of Electronic Markets,

With this issue, Electronic Markets enters its 25th year of publication. It has been an impressive journey from a six-page newsletter published in German to a full-scale international academic journal listed in the Social Sciences Citation Index (SSCI). This quarter century anniversary provides an opportunity to look back on the various stages of Electronic Markets. As shown in Fig. 1, the journal was founded as a newsletter of a research project called "Competence Center Electronic Markets" (CC EM) at the University of St. Gallen in Switzerland. Based on prior publications, in particular the seminal article on electronic markets and hierarchies by Malone et al. (1987), CC EM created a platform funded by several companies to investigate the phenomenon of electronic markets, which was still in its infancy. The diffusion of international as well as open information and communication technologies was conceived as a disruptive force that favors a shift from bilaterally hierarchical to multilateral market-like forms of coordination among businesses. This was well before the "E-Business hype" and some 20 years later, the expectation proved true. Although empirical proof for the "move to the market" hypothesis is still difficult, more electronic platforms linking businesses are available today than ever before. As stated in the review article on "Twenty years of electronic markets research" (Alt and Klein 2011, p. 44) an "extension

\footnotetext{
R. Alt $(\triangle) \cdot$ C. Militzer-Horstmann

Information Systems Institute, University of Leipzig,

Grimmaische Str. 12, 04109 Leipzig, Germany

e-mail: rainer.alt@uni-leipzig.de

C. Militzer-Horstmann

e-mail: militzer-horstmann@wifa.uni-leipzig.de

H.-D. Zimmermann

FHS St. Gallen, University of Applied Sciences,

Rosenbergstrasse 59, 9001 St. Gallen, Switzerland

e-mail: hansdieter.zimmermann@fhsg.ch
}

of market coordination into a broad and diverse array of domains from marketing, to health care or forecasting" took place.

The "EM newsletter" also experienced a quick evolution as already two years later it comprised a total of 32 pages, all of them in English. Then in 1996 the first step towards a more professional journal was taken and the publishing company vdf of the Swiss Federal Institute of Technology in Zurich presented the former newsletter in a new layout (see Fig. 1) and also in a quarterly cycle. After eight issues, Routledgenow part of Taylor \& Francis Group-led the journal to increase its international visibility and also introduced a doubleblind peer review process. Along these lines, eight issues were published and Electronic Markets was established as a truly academic journal with an international editorial board. In 2009 another change occurred and Springer became the publishing company of Electronic Markets. This coincided with the handover of the Editor-in-Chief position from Beat Schmid to Hubert Österle, who were both long-serving professors at the University of St. Gallen.

During all those years, the Editorial Team of Electronic Markets constantly changed as well. In particular, this refers to the position of the Executive Editor, which was usually held by young researchers, who left after a few years to finish their $\mathrm{PhD}$. While this position has seen some fluctuation, Electronic Markets has also experienced stability, as our now Editors-inChief, Rainer Alt and Hans-Dieter Zimmermann have been part of the Editorial Team for many years. Figure 2 provides a snapshot on how the entire team, including the publishers, have evolved since 1991. It shows several milestones and that many colleagues have participated in shaping Electronic Markets to become what it is today. Among the key achievements are:

- Ranking. With the inclusion of Electronic Markets in the SSCI, an impact factor (IF) was calculated, which many recognize as a kind of "gold standard" in scientific 

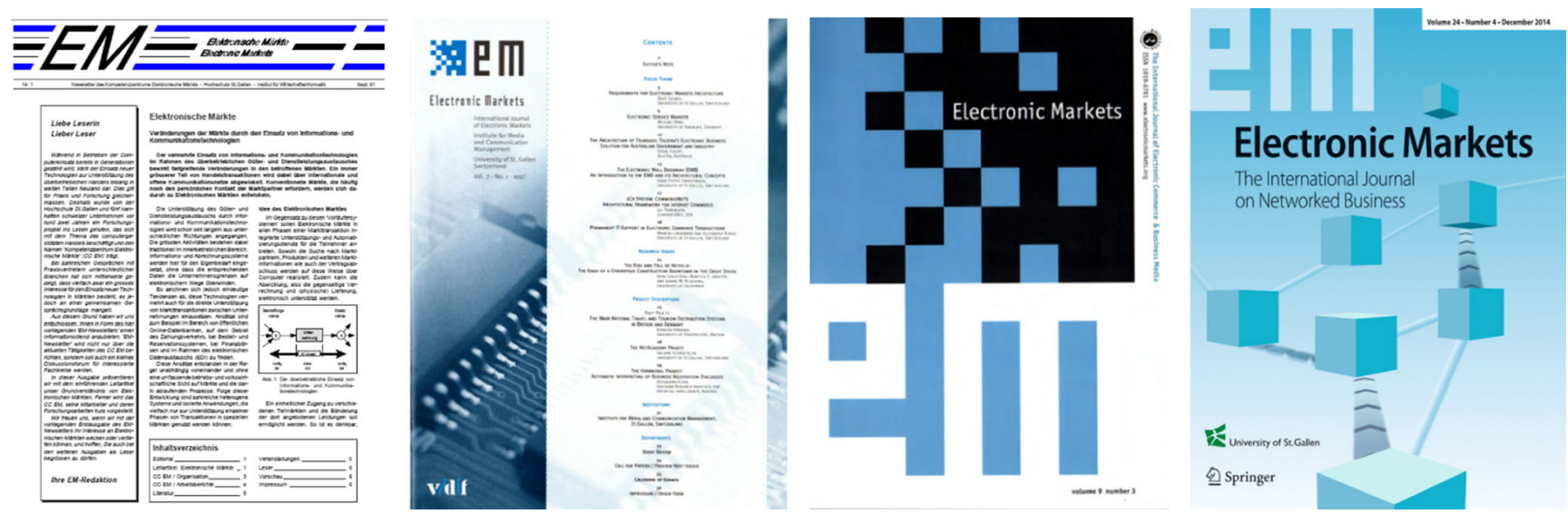

Fig. 1 Evolution of Electronic Markets layout and publishers (from left: internal, vdf, Routledge, Springer)

publishing. In 2013, the IF increased to 0.769 and, clearly, the Editorial Team aims at further improving this factor.

- Sections. Compared to the short one or two-page articles in the early days of Electronic Markets, the journal today covers comprehensive contributions in four sections (research articles, case studies, position/invited papers, and editorials/prefaces/book reviews, see Alt and Österle 2014b, p. 78).

- Scope. With the diffusion of the electronic markets' concept and the distinction of electronic markets in a narrow market-like understanding (short-term relationships, price discovery) and electronic markets in a broader sense (longer-term collaborative relationships) the journal subtitle was adapted to address a broader, yet specific audience.

- Submissions. While the editors in the beginning contacted authors for publications, Electronic Markets now receives a growing number of submissions for the general research and special issue sections. For example, general research submissions increased by $30 \%$ in 2014 compared to 2013 and by almost $45 \%$ when compared to 2012 .

- Efficiency. With the introduction of the double-blind review process in 1998 and with the adoption of an electronic paper handling system in 2007 , the processes in the Editorial Office became more formalized and efficient.

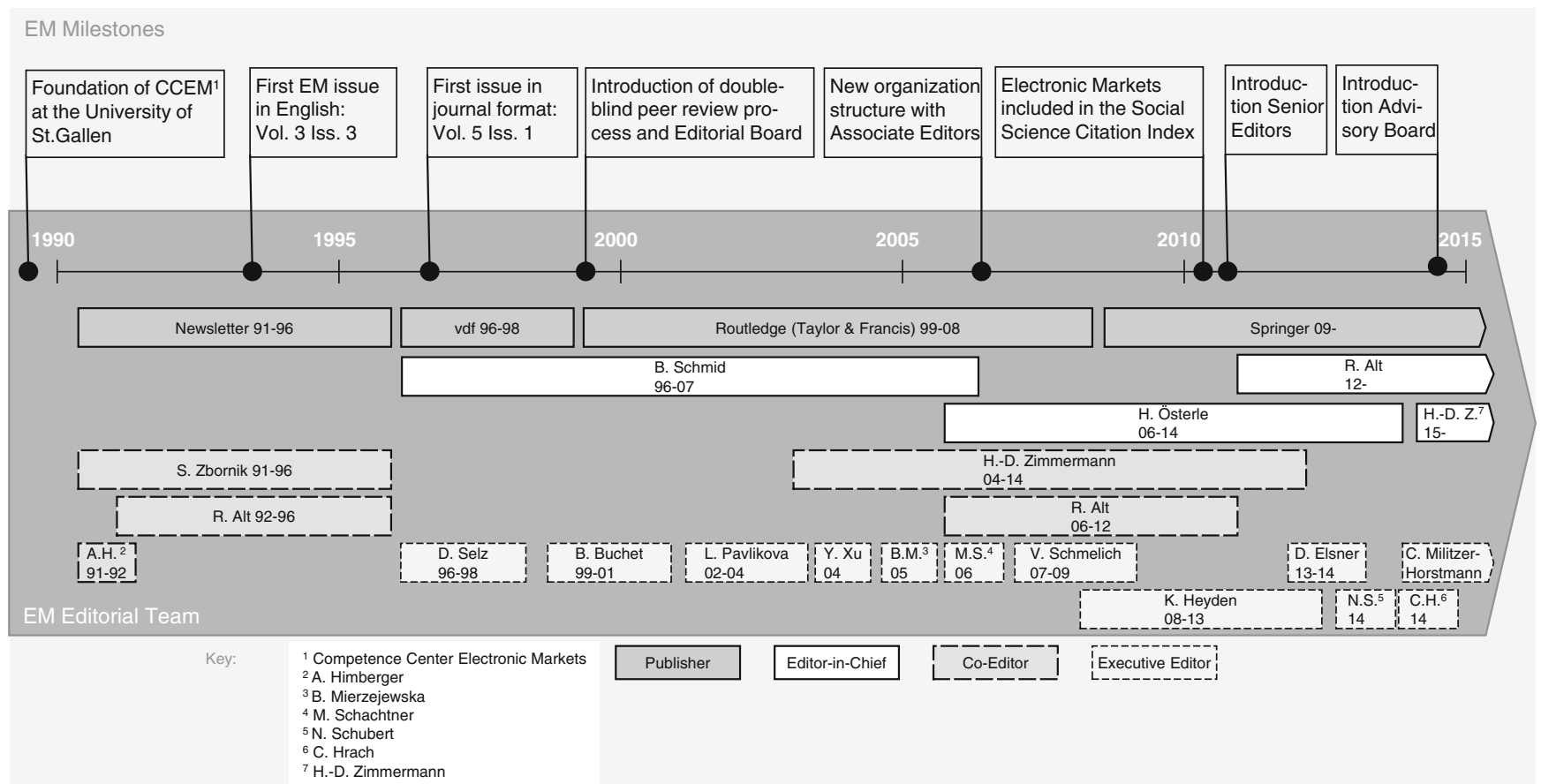

Fig. 2 Evolution of Electronic Markets and its team 
Today, authors receive a first decision on their manuscript within 39 days on average, which is well below our formulated goal of 60 days (Alt and Österle 2014a, p. 2)

- Community. Attaining a high quality for an academic journal relies on the participation of the editorial board. Since 1998, the community of Electronic Markets has grown to include Senior and Associate Editors as well as a large international board of editorial board members. From the perspective of the Editorial Team, the collaboration with all these colleagues is not only exciting, but their feedback is also rewarding for many operational challenges.

As an international journal, Electronic Markets aims to bring together researchers from all major continents in the editorial board. However, the European roots of the journal are still visible and a stronger participation from the Americas as well as from Asia was also discussed at the last Annual Meeting of the Editorial Board, which took place at the International Conference on Information Systems (ICIS 2014) in Auckland, New Zealand. These board meetings were held at the Bled eConference for many years, since this conference shares its tradition on topics of electronic commerce with Electronic Markets (see Clarke and Pucihar 2013). After a poll of the editorial board members, ECIS and ICIS were more recently voted as venues, but overall, board meetings have become occasions where board members meet, where the Editorial Team reports on the development of the journal and where important decisions regarding the journal and its organization are voted on. Among the decision items of the Auckland meeting were:

- Editors-in-Chief. As mentioned in the last Editorial (see Alt and Zimmermann 2014) Hubert Österle, who held the Editor-in-Chief position for 8 years since 2007, stepped down from this position now that he is a professor emeritus (see also the interview in the last issue, (Alt 2014)). We are very happy that Hubert will continue to support Electronic Markets as a member of Electronic Markets' Advisory Board in the future. At the same time, the Editorial Board agreed to appoint Hans-Dieter Zimmermann, a senior lecturer at the Institute for Information and Process Management (IPM) at the University of Applied Sciences in St. Gallen, Switzerland. As mentioned above Hans-Dieter knows Electronic Markets well and has served in several roles since the mid-90s. He was co-editor together with Beat Schmid and has been a Senior Editor since this position was created in 2012. Starting in 2015, Hans-Dieter will share the Editor-in-Chief role with Rainer Alt.

- Senior Editors. All decisions on articles published in Electronic Markets are checked by our Senior Editors.
We highly appreciate that two esteemed Associate Editors of Electronic Markets have agreed to serve as new Senior Editors: Harry Bowman is associate professor of Information and Communication Technology at Delft University of Technology, Netherlands as well as a distinguished professor at Åbo Akademi University, Finland. Judith Gebauer is an associate professor of Management Information Systems at the University of North Carolina Wilmington, USA. Both have been reviewers for Electronic Markets since 2008 and, thus, know the journal well.

- Associate Editors. Additionally, we are happy to welcome four colleagues that followed the Editorial Board's invitations to become Associate Editors: Ulrike Baumöl, a professor for information management at FernUniversität Hagen in Germany, Markus Bick, professor for business information systems at ESCP Europe Business School in Berlin, Germany, Marianna Sigala, an associate professor of service management in tourism at the University of the Aegean in Greece and Charles Steinfield, who is a professor at Michigan State University's (USA) department of media and information. All four of them have been members of our Editorial Board for years and have shown their dedication to our journal.

- Editorial Board Members. Finally, the Editorial Board agreed to appoint seven new editorial board members, who have repeatedly served as reviewers for Electronic Markets already. New board members are Mark de Reuver, an assistant professor at Delft University of Technology, Netherlands, Peter Gomber, professor for e-finance at Goethe University Frankfurt, Germany, Shengnan Han, an associate professor at Stockholm University, Sweden, Maria Madlberger, professor for marketing at Webster Vienna Private University in Austria, Shahrokh Nikou, lecturer at Åbo Akademi University, Finland, Reima Suomi, professor at the University of Turku, Finland and the Huazhong Normal University in China and Frédéric Georges Thiesse, professor for business information systems and systems development at Julius-Maximilians-University Würzburg, Germany. We are happy that they have also followed our invitations.

Besides the organizational changes, two awards were communicated at the Editorial Board meeting. The first is the "Outstanding Reviewer Award", which was introduced in 2013. For the 2014 award, all reviews submitted in 2014 were considered and the winners were chosen based on a set of quality criteria. It is our pleasure to announce five colleagues that have convincingly provided 
constructive feedback and recommendations to authors. These are Ulrike Baumöl from FernUniversität Hagen, Maria Madlberger from Webster Vienna Private University, Shahrokh Nikou from Åbo Akademi University, Boris Otto from Technische Universität Dortmund in Germany and Mark de Reuver from Delft University of Technology. The second award refers to the "Paper of the Year", a competition, which was conducted for the first time. To determine the two papers that qualified, all 2013 articles published in Electronic Markets were analyzed from a quantitative (downloads and citations in 2014) and a qualitative (reviews and novelty) perspective. We wish to congratulate Ken J. Corley, Zack Jourdan and W. Rhea Ingram (2013) for their paper on "Internet marketing: a content analysis of the research" and Kai Reimers, Robert B. Johnston, Xunhua Guo, Stefan Klein, Bin Xie and Mingzhi Li (2013) for their paper "Novice-based data collection methods for the study of IOIS: Practice probes and learning communities".

Last but definitely not least, we want to thank all the reviewers who contributed to the quality of Electronic Markets through their work in 2014. A complete name list of all colleagues that provided reviews for Electronic Markets in 2014 is shown below. We are aware that reviewing is time-consuming and highly value the effort of each reviewer. This was one reason for us to enforce desk-reject decisions more strictly, since only papers with a good fit regarding the scope of Electronic Markets, academic rigor as well as relevance-thus, a minimal probability of becoming accepted-should enter the review process. At the same time, we hope to give back some appreciation with the still young award certificates. In case you have suggestions for further improvements or any other feedback, the Editorial Team is always open to hear from you.

After this information about the journal itself, let us present the contents of volume 25 's first issue. It comprises three articles in the special issue section and two in the general research section. The topic of the special issue is also currently relevant in the public and political discussion, since the question of how energy is produced, distributed and consumed bears much potential with many perspectives being based on the innovative use of IT among many players. In particular, electricity is often referred to as a commodity that is standardized and easy to describe, which makes it suitable for electronic markets (see Malone et al. 1987). We would like to thank our guest editors Johann Kranz and Lutz M. Kolbe from the University of Göttingen in Germany, Chulmo Koo from Kyung Hee University in South Korea and Marie-Claude Boudrea from the University of Georgia, USA, for making this special issue possible. They will introduce the three papers of their special issue in the elaborate preface for this section (Kranz et al. 2015).

In the general research section both research papers address the subject of innovation while pursuing different qualitative research approaches. The first paper titled "SNA-based innovation trend analysis in software service networks" by Kibae Kim, Wool-Rim Lee and Jörn Altmann considers service networks as open innovation systems and looks at the dynamics of service network, more specifically at the changes of network positions over time. For the research a service network was built upon empirical data with each node representing a Software-as-a-Service (SaaS). The research analyzed the trend of positions of several representative software services and led to three conclusions: first, the software services show innovation adoption life cycle behaviors within the network, second, software services achieve positions that interconnect nodes of the entire network or some services achieve core positions within a cluster of software services, and, third, an innovation trend appears at service category level not just by a single service.

The second general research paper is titled "Integrated long- and short-term valuation of IT innovation investments" and is authored by Björn Häckel, Vasko Isakovic and Florian Moser. The authors address the given time gap between IT innovation investments and their uncertain long-term value contribution in their research. Therefore the paper proposes an integrated long- and short-term valuation approach that incorporates an IT innovation investment's effect on the value of a company's IT portfolio following the design science approach. A real-world application example illustrates the theoretical model and the valuation approach was analyzed using the described application example through a sensitivity analysis.

We hope you enjoy reading all of these articles and hope you also consider Electronic Markets for publishing your own work.

Best regards from Leipzig and St. Gallen,

Rainer Alt, Carsta Militzer-Horstmann, Hans-Dieter Zimmermann 


\section{Reviewers in 2014}

Babak Abedin

Abubakar Mohammed Abubakar

Nitin Aggarwal

Paul Alpar

Volker Bach

Ulrike Baumöl

Steven Bellman

Rainer Boehme

Flavio Bonfatti

Harry Bouwman

Ivan Breskovic

Gordon Burtch

Cinzia Cappiello

Hsueh-Hsien Chang

Christy Cheung

Namho Chung

Anastasia Constantelou

John Corley

Esmeralda Crespo Almendros

Kevin Crowston

Rachel Cummings

Hua Dai

Mark de Reuver

Yi Ding

Isao Echizen

Morten Falch

Matthias Fuchs

Denise Gengatharen

Rüdiger Grimm

Netsanet Haile

Shengnan Han

Tuomas Harviainen
Thomas Hess
Holger Hoffmann
Christopher Holland
Jussi Holopainen
Val Hooper
Wolfram Höpken
William Hunter
Alessandro Inversini
Marijn Janssen
Panagiotis Kassianidis
Jana Korunovska
Helmut Krcmar
Ulrike Lechner
Andy Lee
Jörg Leukel
Szu-Yin Lin
June Lu
André Ludwig
Maria Madlberger
Christian Maier
Matti Mäntymäki
David Mendonca
Martin Mocker
Eric Molin
Shahrokh Nikou
Fevzi Okumus
Guido Ongena
Boris Otto
Anastasia Papazafeiropoulou
Eduardo Para Lopez
Ralf Peters

\author{
Bharat Rao \\ Olaf Reinhold \\ James Richard \\ Ryan Riordan \\ Steve Sawyer \\ Daniel Schlagwein \\ Detlef Schoder \\ Kim Serota \\ Marianna Sigala \\ Mimmi Sjöklint \\ Sarah Spiekermann \\ Barney Tan \\ Stella Tian \\ Verena Tiefenbeck \\ Paul Timmers \\ Waldemar Toporowski \\ Luba Torlina \\ Indrit Troshani \\ Nils Urbach \\ Robert Verburg \\ Johan Versendaal \\ Pavlos Vlachos \\ Liad Wagman \\ Yun Wan \\ Dan Wang \\ Jason Whalley \\ Xiaolin Zheng \\ Lina Zhou \\ Hans-Dieter Zimmermann \\ Alf Zugenmaier
}

\section{References}

Alt, R. (2014). Electronic market research and the impact of consumerization: an interview with Hubert Österle. Electronic Markets, 24(4), 251-253. doi:10.1007/s12525-014-0175-5.

Alt, R., \& Klein, S. (2011). Twenty years of electronic markets researchlooking backwards towards the future. Electronic Markets, 21(1), 41-51. doi:10.1007/s12525-011-0057-z.

Alt, R., \& Österle, H. (2014a). Electronic markets and practice-orientation. Electronic Markets, 24(1), 1-3. doi:10.1007/s12525-0140152-z.

Alt, R., \& Österle, H. (2014b). Electronic markets and journal sections. Electronic Markets, 24(2), 77-79. doi:10.1007/s12525-014-0159-5.

Alt, R. \& Zimmermann, H.-D. (2014), Editorial 24/4: Electronic Markets and business models. Electronic Markets, 24(4), 231-234. doi: 10. 1007/s12525-014-0178-2.
Clarke, R., \& Pucihar, A. (2013). Electronic interaction research 1988 2012 through the lens of the Bled eConference. Electronic Markets, 23(4), 271-283. doi:10.1007/s12525-013-0144-4.

Corley, J. K., II, Jourdan, Z., \& Ingram, W. R. (2013). Internet marketing: a content analysis of the research. Electronic Markets, 23(3), 177204. doi:10.1007/s12525-012-0118-y.

Kranz, J., Kolbe, L. M., Koo, C., Boudreau, M.-C. (2015). Smart energy: where do we stand and where should we go? Electronic Markets, 25(1). doi:10.1007/s12525-015-0180-3.

Malone, T. W., Yates, J., \& Benjamin, R. I. (1987). Electronic markets and electronic hierarchies. Communications of the ACM, 30(6), 484-497. doi:10.1145/214762.214766.

Reimers, K., Johnston, R. B., Guo, X., Klein, S., Xie, B., \& Li, M. (2013). Novice-based data collection methods for the study of IOIS: practice probes and learning communities. Electronic Markets, 23(4), 285293. doi:10.1007/s12525-013-0126-6. 